NASA/TM-2003-212622

\title{
PWM Switching Frequency Effects on Eddy Current Sensors for Magnetically Suspended Flywheel Systems
}

Ralph Jansen

University of Toledo, Toledo, Ohio

Ramon Lebron

Glenn Research Center, Cleveland, Ohio

Tim Dever

QSS Group, Inc., Cleveland, Ohio

Art Birchenough

Glenn Research Center, Cleveland, Ohio 
Since its founding, NASA has been dedicated to the advancement of aeronautics and space science. The NASA Scientific and Technical Information (STI) Program Office plays a key part in helping NASA maintain this important role.

The NASA STI Program Office is operated by Langley Research Center, the Lead Center for NASA's scientific and technical information. The NASA STI Program Office provides access to the NASA STI Database, the largest collection of aeronautical and space science STI in the world. The Program Office is also NASA's institutional mechanism for disseminating the results of its research and development activities. These results are published by NASA in the NASA STI Report Series, which includes the following report types:

- TECHNICAL PUBLICATION. Reports of completed research or a major significant phase of research that present the results of NASA programs and include extensive data or theoretical analysis. Includes compilations of significant scientific and technical data and information deemed to be of continuing reference value. NASA's counterpart of peerreviewed formal professional papers but has less stringent limitations on manuscript length and extent of graphic presentations.

- TECHNICAL MEMORANDUM. Scientific and technical findings that are preliminary or of specialized interest, e.g., quick release reports, working papers, and bibliographies that contain minimal annotation. Does not contain extensive analysis.

- CONTRACTOR REPORT. Scientific and technical findings by NASA-sponsored contractors and grantees.
- CONFERENCE PUBLICATION. Collected papers from scientific and technical conferences, symposia, seminars, or other meetings sponsored or cosponsored by NASA.

- SPECIAL PUBLICATION. Scientific, technical, or historical information from NASA programs, projects, and missions, often concerned with subjects having substantial public interest.

- TECHNICAL TRANSLATION. Englishlanguage translations of foreign scientific and technical material pertinent to NASA's mission.

Specialized services that complement the STI Program Office's diverse offerings include creating custom thesauri, building customized databases, organizing and publishing research results ... even providing videos.

For more information about the NASA STI Program Office, see the following:

- Access the NASA STI Program Home Page at http://www.sti.nasa.gov

- E-mail your question via the Internet to help@sti.nasa.gov

- Fax your question to the NASA Access Help Desk at 301-621-0134

- Telephone the NASA Access Help Desk at 301-621-0390

- Write to:

NASA Access Help Desk

NASA Center for AeroSpace Information 7121 Standard Drive

Hanover, MD 21076 
NASA/TM-2003-212622

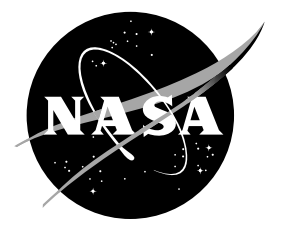

\section{PWM Switching Frequency Effects on Eddy Current Sensors for Magnetically Suspended Flywheel Systems}

Ralph Jansen

University of Toledo, Toledo, Ohio

Ramon Lebron

Glenn Research Center, Cleveland, Ohio

Tim Dever

QSS Group, Inc., Cleveland, Ohio

Art Birchenough

Glenn Research Center, Cleveland, Ohio

Prepared for the

First International Energy Conversion Engineering Conference

sponsored by the American Institute of Aeronautics and Astronautics

Portsmouth, Virginia, August 17-21, 2003

National Aeronautics and

Space Administration

Glenn Research Center 
Available from

NASA Center for Aerospace Information 7121 Standard Drive

Hanover, MD 21076
National Technical Information Service 5285 Port Royal Road Springfield, VA 22100

Available electronically at http://gltrs.grc.nasa.gov 


\section{PWM SWITCHING FREQUENCY EFFECTS ON EDDY CURRENT SENSORS FOR MAGNETICALLY SUSPENDED FLYWHEEL SYSTEMS}

\author{
Ralph H. Jansen \\ University of Toledo \\ Toledo, Ohio
}

\author{
Ramon Lebron \\ NASA Glenn Research Center \\ Cleveland, Ohio
}

\author{
Timothy P. Dever \\ QSS Group, Inc. \\ Cleveland, Ohio
}

\author{
Arthur G. Birchenough \\ NASA Glenn Research Center \\ Cleveland, Ohio
}

\begin{abstract}
A flywheel magnetic bearing (MB) pulse width modulated power amplifier (PWM) configuration is selected to minimize noise generated by the PWMs in the flywheel position sensor system. Two types of noise are addressed: beat frequency noise caused by variations in PWM switching frequencies, and demodulation noise caused by demodulation of high order harmonics of the switching voltage into the MB control band. Beat frequency noise is eliminated by synchronizing the PWM switch frequencies, and demodulation noise is minimized by selection of a switching frequency which does not have harmonics at the carrier frequency of the sensor. The recommended MB PWM system has five synchronized PWMs switching at a non-integer harmonic of the sensor carrier.
\end{abstract}

\section{$\underline{\text { Introduction }}$}

NASA Glenn Research Center (GRC) sponsors flywheel technology development and deployment for spacecraft applications [1]. Flywheel systems can be used for energy storage as an alternative to batteries and reaction wheels in space systems. Also, flywheel modules can be installed in an arrangement which provides both energy storage and momentum control; this kind of system is called an Integrated Power and Attitude Control System (IPACS). A flywheel system is composed of several flywheel modules, along with their supporting electronics. The electronics package operates the motor/generators, the MBs and the telemetry.

Energy storage flywheel applications benefit from high energy density, high power density, long life, deep depth of discharge, and broad operating temperature ranges available with flywheels. In an IPACS configuration, an additional mass savings can be achieved through the combination of the energy storage and the attitude control functions into one system.
Flywheel modules for space use are designed to maximize energy density and minimize losses; a representative flywheel module is shown in Figure 1. The flywheel rotor features a high strength carbon fiber rim which stores energy kinetically, and a coaxial motor/generator is used to transfer energy to and from the wheel. The motor, MBs, and touchdown bearings are located on each end of the hub. Stationary components, such as position and temperature sensors, connectors, and wiring harnesses, are located within the housing structure.

The flywheel active MB control system uses a position feedback controller to levitate the rotor by adjusting a set of electromagnets [2]. This controller has five degrees of freedom: two radial degrees of freedom at each end of the rotor and one degree of freedom axially. The radial MB moves the rotor in the $X 1$ and $Y 1$ radial directions, and the combination MB actuates in the $X 2$ and $Y 2$ radial directions, as well as the $Z$ (axial) direction.

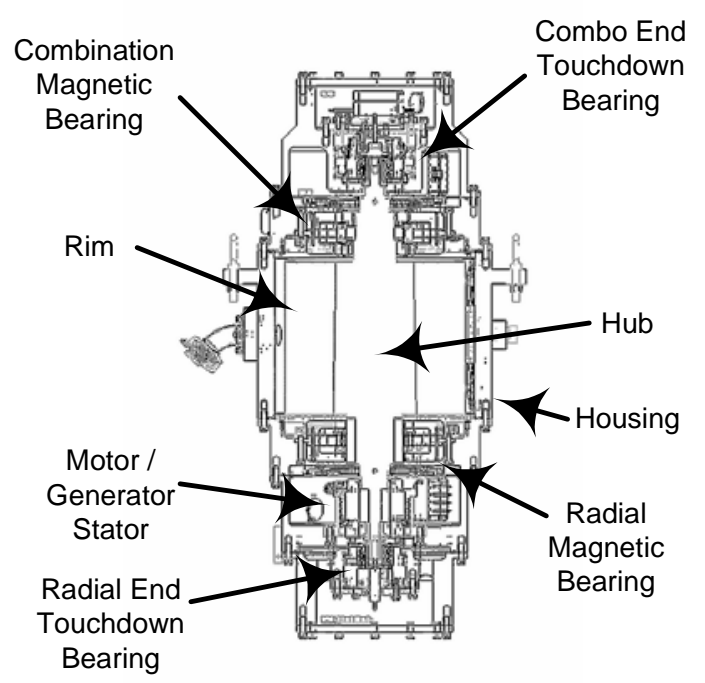

Figure 1. G2 Flywheel Module 


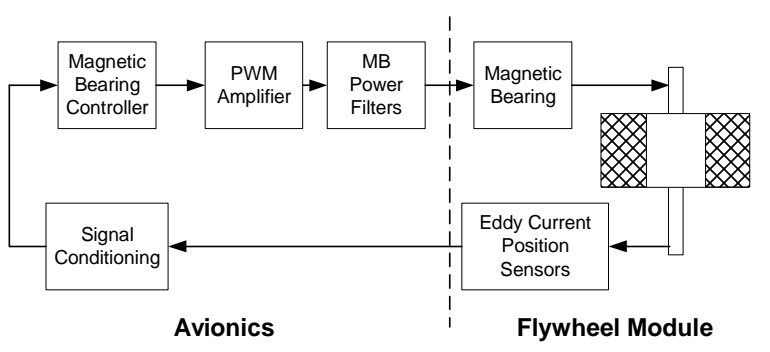

Figure 2. Active MB System

The PWMs drive current through the power filters and into the MB actuators; the resultant magnetic fields in the air gaps between the bearing stator and rotor produce a net force on the rotor, which accelerates, changing its position. Five sets of position sensors measure shaft locations along the MB axes, and this sensor signal is conditioned (scaled, offset and filtered) and passed back to the MB controller, which compares the desired rotor position to the actual position and updates the command signal to the PWMs.

The minimum required closed loop bandwidth of the MB system depends on the flywheel module design; the modules being tested at GRC require control of modes up to $800 \mathrm{~Hz}$. The bandwidth is typically limited by the actuator, power filter and PWM. Other factors which may limit bandwidth are loop time of the digital controller, and sensor signal conditioning. A MB control algorithm which is too complex may not execute in the desired loop time; increasing loop time to allow execution will negatively impact bandwidth. Also, if noise present at the sensors is significant, extensive filtering may be required; lag due to this filtering will also reduce controller bandwidth.

\section{Problem Statement}

Non-contact eddy current position sensors are used to measure rotor location in the flywheel MB control system; these sensors rely on an amplitude modulation (AM) scheme. Switching PWMs are an attractive choice for driving the MB actuators, since they are more compact and less lossy than linear amplifiers; however, incorrect implementation of PWMs can contribute significant noise to the position sensor system, making control more difficult. This paper addresses issues that arise with the use of switching PWMs in active MB systems.

Two types of noise which can be generated in the position sensors of a multiple axis PWM MB system are beat frequency noise and demodulation noise. Beat frequency noise is

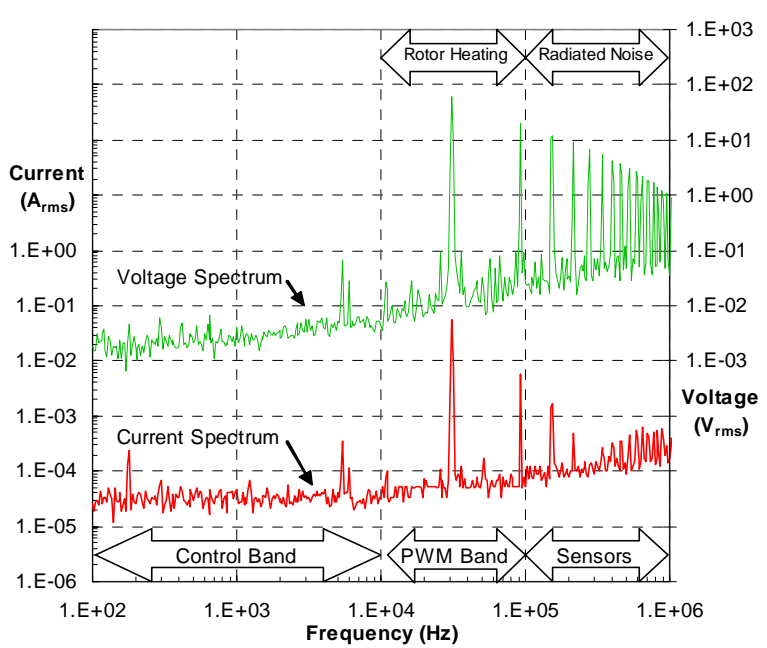

Figure 3. Power Amplifier Spectrum

generated due to variations in individual PWM switching frequencies, and demodulation noise occurs when the PWM switching frequency is selected such that one of its harmonics is near the sensor demodulation frequency.

In order to evaluate the impact of this electromagnetic noise on the flywheel system, it is convenient to consider the current and voltage applied by the PWM to the magnetic actuator in the frequency domain (Figure 3). This spectrum can be divided into three general regions: the control band, the PWM band, and the sensor band. The MB control band extends from $\mathrm{DC}$ to $10 \mathrm{kHz}$. Ideally, only currents and voltages generated by MB controller commands should be present in this region. The next region up is the PWM switching band, which extends from $10 \mathrm{kHz}$ to $100 \mathrm{kHz}$; the fundamental switching frequencies of the PWMs are within this frequency range. The sensor band is the final portion of the spectrum, extending between $100 \mathrm{kHz}$ and $1 \mathrm{MHz}$; the carrier frequency of the eddy current position sensors fall into this range (the sensors used in the GRC flywheels are operated at $500 \mathrm{kHz}$ and $1 \mathrm{MHz}$ ).

Electromagnetic noise is radiated by operating MB actuators, and measurements have shown that this radiated noise is picked up by the sensors. Although the radiated noise is broad band, we are mainly concerned with noise near the carrier frequency of the sensors. This paper will be limited to measurements on the sensors operating at $500 \mathrm{kHz}$, because they are utilized in the more sensitive control loops. Noise radiated near the $500 \mathrm{kHz}$ carrier frequency is detected at the sensor head and demodulated in the eddy current 
sensor conditioning electronics, which brings it into the control bandwidth of the MB. For example, a noise peak radiated by a PWM at $499 \mathrm{kHz}$ will appear, after demodulation, as a $1 \mathrm{kHz}$ noise input to the MB controller. Since the control system doesn't significantly attenuate until $\sim 10 \mathrm{kHz}$, we ideally would like a low noise environment in the $490-510 \mathrm{kHz}$ region.

\section{Approach}

The original MB system configuration used separate, non-synchronized PWMs on each of the five control axes, all switching at factory-defined frequencies which varied between $26 \mathrm{kHz}$ and $31 \mathrm{kHz}$. This configuration had considerable beating and demodulation noise problems.

Separate techniques were developed to address these two noise types. Beat frequency noise was addressed by synchronizing all of the PWMs on a single oscillator, thus eliminating the variations in switching frequency which cause the noise, and demodulation noise was addressed by choosing the synchronized PWM frequency such that its higher harmonics were distanced from the sensor carrier frequency. A test matrix was developed to test these two methods individually. Relative performance of each method was quantified by recording the $\mathrm{MB}$ position sensor noise spectra while levitating the flywheel at 0 RPM, for each of the test cases.

The test matrix details are presented in Table 1. Eight test cases are presented. Test A combines both noise elimination methods, and presents the best case solution, while test $\mathrm{H}$ deliberately generates both beat frequency and demodulation noise. Tests B-D are a controlled study the effects of beat frequency noise, and tests E-G study demodulation noise. The tests were designed so that the effects were most evident on the radial (X1-Y1) actuator. In order to simplify data presentation, a single noise spectrum was created for each test case by summing the $\mathrm{X} 1$ and Y1 spectra together. Beat frequencies were studied by synchronizing four PWMs at a frequency known not to cause demodulation noise, and moving the frequency of the fifth PWM (X1) in a controlled way. Demodulation noise was generated by synchronizing all five PWMs at various frequencies intended to generate demodulation noise.
Table 1. Noise Testing Matrix

\begin{tabular}{|c|l|l|l|c|}
\hline Cell & \multicolumn{1}{|c|}{ Test } & Config & \multicolumn{1}{|c|}{ Harmonic } & F $_{\text {PWM }}$ \\
\hline A & best case & synched & $15.41 n$ & $32,437.6$ \\
\hline B & beating & X1 & $15.41 n+50$ & $32,487.6$ \\
& & Other 4 & $15.41 n$ & $32,437.6$ \\
\hline C & beating & X1 & $15.41 n+100$ & $32,537.6$ \\
& & Other 4 & $15.41 n$ & $32,437.6$ \\
\hline D & beating & X1 & $15.41 n+200$ & $32,637.6$ \\
& & Other 4 & $15.41 n$ & $32,437.6$ \\
\hline E & demod & All & $15 n$ & $33,333.3$ \\
\hline F & demod & All & $15 n+45$ & $33,336.3$ \\
\hline G & demod & All & $15 n+90$ & $33,339.3$ \\
\hline H & beating \& & X1 & $15 n+90+50$ & $33,389.3$ \\
& demod & Other 4 & $15 n+90$ & $33,339.3$ \\
\hline
\end{tabular}

\section{$\underline{\text { Results }}$}

All cases in the test matrix described in Table 1 were run. In this section, details of each test are given, and results are presented. Performance of best and worst case configurations is discussed, and comments on system configuration beyond the PWM noise setup (i.e. grounding and shielding) are provided.

\section{Beat Frequency Noise}

When PWM amplifiers with different switching frequencies are used to drive coils in the same $\mathrm{MB}$ actuator, beat frequency noise can result; this noise is picked up by the position sensors for that plane.

Test cells B, C, and D illustrate the beat frequency noise effect; this test is summarized in Table 2. For these tests, the PWMs for the $Y 1, X 2, Y 2$, and $\mathrm{Z}$ axes are all synchronized at $32.437 \mathrm{kHz}$; this frequency was specifically selected to minimize the other major noise source (demodulation noise). The X1 PWM switching frequency was then varied from the nominal frequency by 50,100 , and $200 \mathrm{~Hz}$.

Results of test cells B-D are plotted in Figure 4. Distinct beat frequencies can easily be observed, one for each test case, at 50, 100 and $200 \mathrm{~Hz}$. Note that the magnitude of the beating is greatest when the PWM frequencies are closest (test B).

Table 2. Beat Frequency Test Matrix

\begin{tabular}{|c|l|l|l|c|}
\hline Cell & \multicolumn{1}{|c|}{ Test } & Config & \multicolumn{1}{|c|}{ Harmonic } & F $_{\mathrm{PWM}}$ \\
\hline B & beating & $\mathrm{X} 1$ & $15.41 \mathrm{n}+50$ & $32,487.6$ \\
& & Other 4 & $15.41 \mathrm{n}$ & $32,437.6$ \\
\hline C & \multirow{2}{*}{ beating } & $\mathrm{X} 1$ & $15.41 \mathrm{n}+100$ & $32,537.6$ \\
& & Other 4 & $15.41 \mathrm{n}$ & $32,437.6$ \\
\hline D & \multirow{2}{*}{ beating } & $\mathrm{X} 1$ & $15.41 \mathrm{n}+200$ & $32,637.6$ \\
& & Other 4 & $15.41 \mathrm{n}$ & $32,437.6$ \\
\hline
\end{tabular}


Noise from the utility power is also present on all of the sensor spectra. It can be seen at its fundamental of $60 \mathrm{~Hz}$, and at its harmonics; in Figure 4 the fundamental, second, and third harmonics can be easily seen.

\section{Demodulation Noise}

The PWMs used in these tests were the two-state type, operated on an 80V DC bus. When a zero current is commanded on this type PWM, it generates a square wave of $50 \%$ duty cycle. This voltage is applied to the MB actuators, and the resulting currents have content at the switching frequency and its harmonics. A Fourier decomposition of this square waveform was done to determine the theoretical magnitude of the voltage at frequencies near the demodulation frequency of the position sensors. The ideal square wave and the function reconstructed from summing the first nineteen terms of the Fourier series are shown in Figure 5 (note that square waves contain only odd harmonics). There is still content in the $15^{\text {th }}$ harmonic; this is the region of interest, as radiated noise from a single (or multiple) PWM at these frequencies can be demodulated into the control band by the sensor system, and introduced to the MB control algorithm.

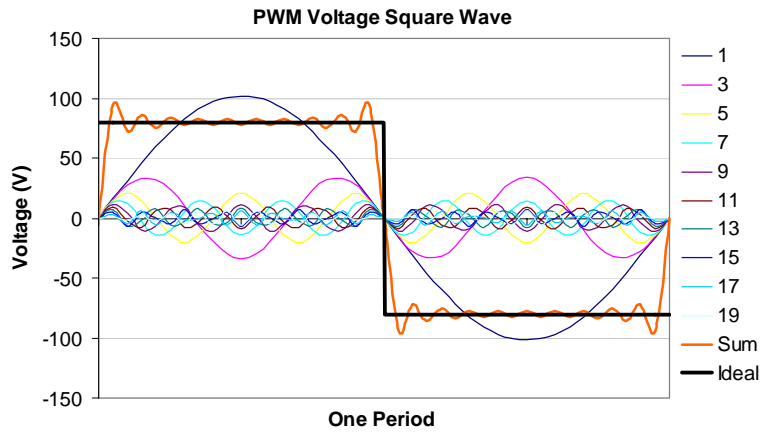

Figure 5. 80V Square Wave (Theoretical)

Figure 6 shows the output voltage frequency spectrum of a two stage PWM, fundamental switching frequency $30,600 \mathrm{~Hz}$, run on an $80 \mathrm{VDC}$ source (solid line), along with the theoretical 80 VDC harmonic voltage magnitudes (diamonds). The frequency of each harmonic is shown above each peak, and the harmonic number is shown below. Note that the actual spectrum follows the theoretical, although it gradually drops away from the ideal calculation due to line inductance and second order effects.

The carrier frequency of the position sensors of interest in the GRC system is $500 \mathrm{kHz}$. The $15^{\text {th }}$ and $17^{\text {th }}$ harmonics bracket the carrier frequency in the example system plotted in Figure 6.

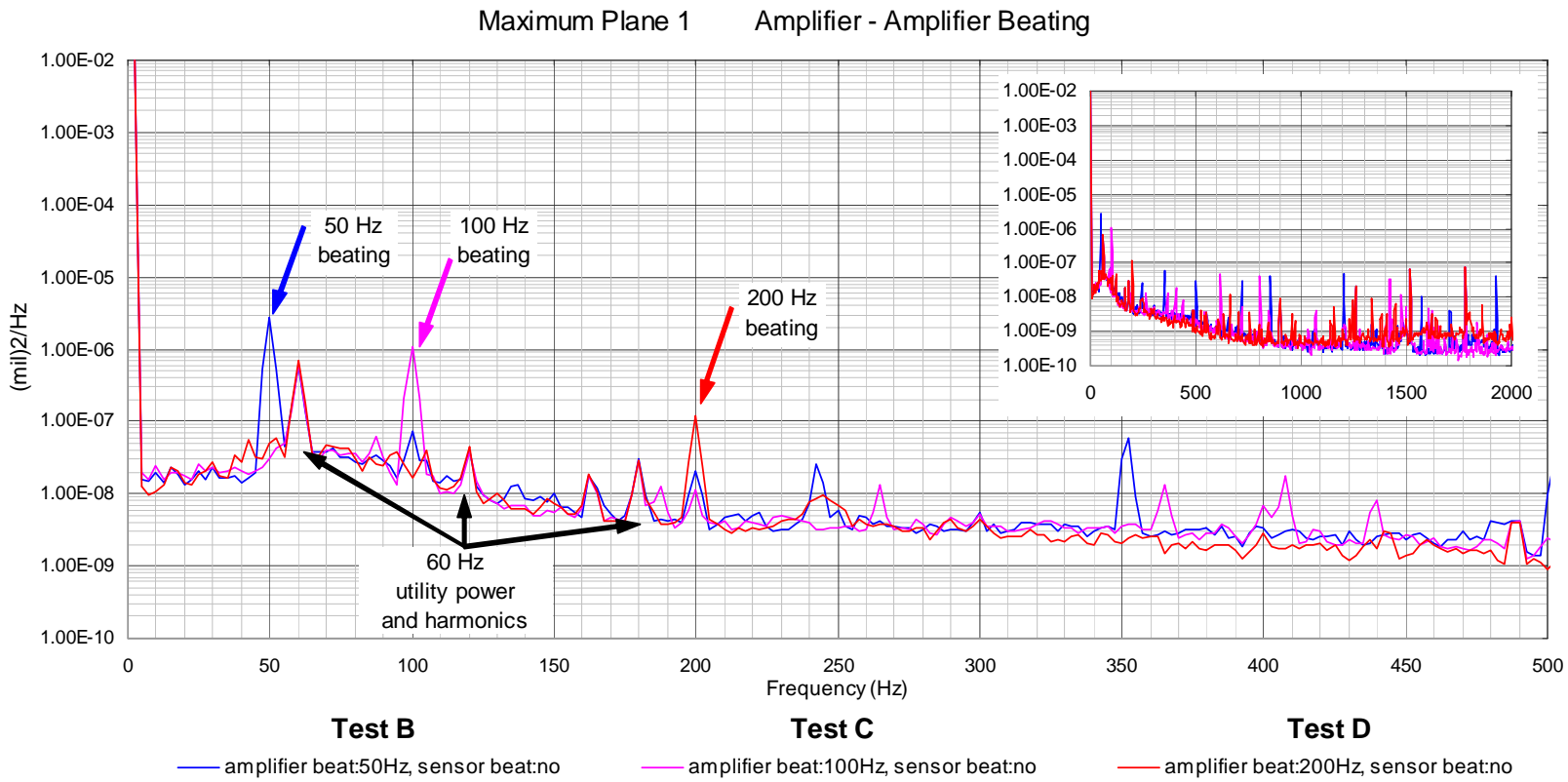

Figure 4. Beat Frequency Noise Spectrum 


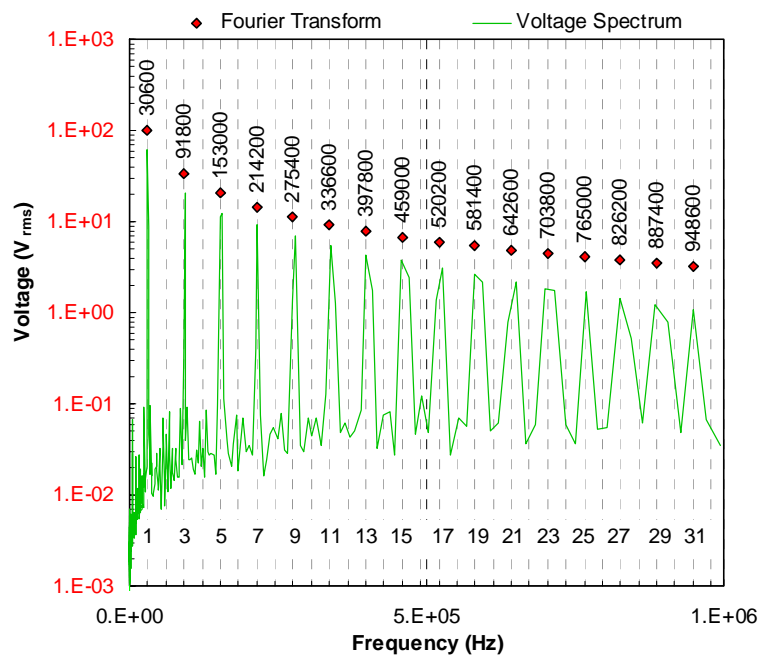

Figure 6. Actual vs. Theoretical PWM Voltage (80 $\vee$ bus)

A worst case scenario for demodulation noise would be selection of the PWM switching frequency such that one of its harmonics was an odd integer multiple of the sensor carrier frequency, or

$$
\mathrm{F}_{\text {sensor }} / \mathrm{F}_{\mathrm{pwm}}=\mathrm{n}
$$

where $\mathrm{n}$ is an odd integer. A series of test cases were run to quantify this effect; the test is summarized in Table 3. All five PWMs were synchronized for these tests; the switching frequency was set so the $15^{\text {th }}$ harmonic was exactly $500 \mathrm{kHz}$, per Equation 1, in test $\mathrm{E}$. The switching frequency was then bumped up by 3 and $6 \mathrm{~Hz}$ in tests $\mathrm{F}$ and $\mathrm{G}$, which correspond to 45 $\mathrm{Hz}\left(3 \mathrm{~Hz} * 15^{\text {th }}\right.$ harmonic) and $90 \mathrm{~Hz}$ changes at the demodulation frequency. Cell $A$ is the best case scenario for this test, with all of the PWMs synchronized to a non-integer harmonic below the $15^{\text {th }}$.

Table 3. Demodulation Frequency Noise Test

\begin{tabular}{|c|l|l|l|c|}
\hline Cell & \multicolumn{1}{|c|}{ Test } & Config & \multicolumn{1}{|c|}{ Harmonic } & F $_{\text {PWM }}$ \\
\hline A & best case & synched & $15.41 n$ & $32,437.6$ \\
\hline E & demod & All & $15 n$ & $33,333.3$ \\
\hline F & demod & All & $15 n+45$ & $33,336.3$ \\
\hline G & demod & All & $15 n+90$ & $33,339.3$ \\
\hline
\end{tabular}

Figure 7 shows the results for the demodulation noise and best case tests. The best case (cell A) spectrum has peaks only at the utility power frequency $(60 \mathrm{~Hz})$ and its harmonics. Due to low frequency measurement limitations of the spectrum analyzer, it is difficult to see all of the effects in the spectral measurement for cell $E$; however, a broad shoulder can be seen between $10-50 \mathrm{~Hz}$ for this test cell. Cell $\mathrm{F}$ is an excellent illustration of the demodulation noise effect with a strong demodulation frequency at $45 \mathrm{~Hz}$, and test $\mathrm{G}$ shows demodulation noise at $90 \mathrm{~Hz}$ and its harmonics; the second through fifth harmonics can easily be seen in the Test $\mathrm{G}$ data.

Ideal selection of the synchronized PWM switching frequency would place the sensor demodulation frequency well within the two

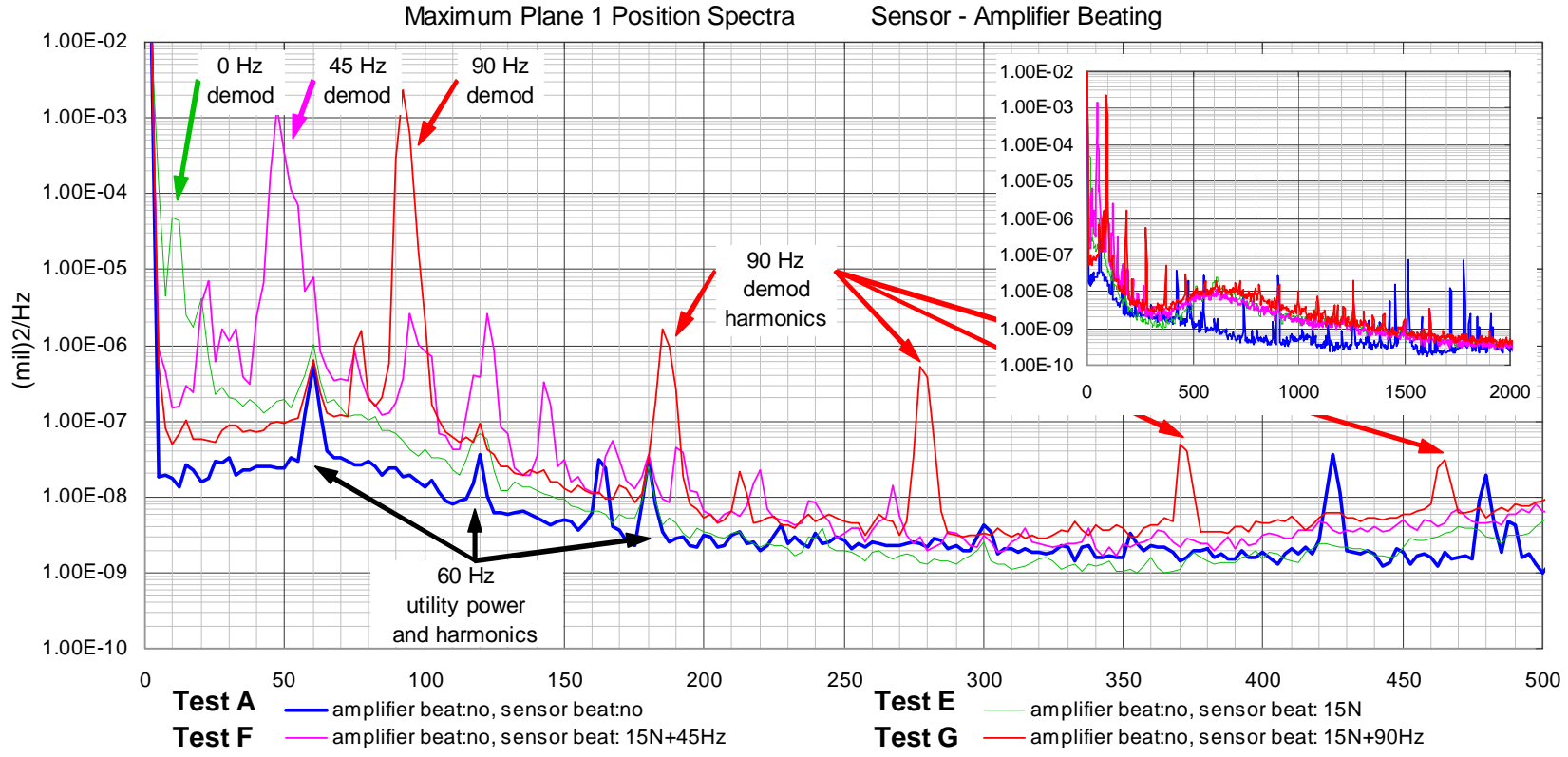

Figure 7. Demodulation Noise Spectrum 
nearby PWM harmonics. Figure 8 was generated to allow easy visualization of this selection process. The sensor carrier frequency is plotted along the vertical axis, and the possible PWM frequencies, along the horizontal. Each individual black line plotted on the chart represents an odd harmonic of the PWM frequency plotted as a sensor frequency vs. the PWM fundamental. Thus the lowest line on the chart has slope 1, then next, slope 3, etc. Since our sensor carrier frequency is $500 \mathrm{kHz}$, the ideal PWM switching frequency would be selected by drawing a line up from the horizontal axis, and choosing a point on the $500 \mathrm{kHz}$ sensor carrier line which is halfway between two harmonic lines.

Our commercial PWMs are limited to switching frequencies between $31-34 \mathrm{kHz}$, which places us between the $15^{\text {th }}$ and $17^{\text {th }}$ harmonics, per Figure 8. During testing, the harmonic number selected was $n=15.41$, or $F_{P W M}=32,437.6 \mathrm{~Hz}$, because this frequency does not have any odd integer PWM harmonics near the carrier frequency. This test frequency is plotted on Figure 8 in blue. It was selected empirically, before Figure 8 was developed; note that a PWM frequency closer to $31 \mathrm{kHz}$ would be a better selection, as it would be closer to the center point between the $15 \mathrm{ht}$ and $17^{\text {th }}$ harmonics.

\section{Best vs. Worst Configuration}

The final comparison that was made was between the best and worst case configurations, as described in Table 4 . In the best case for this testing, all five PWMs were synchronized, and the switching frequency was not an odd integer multiple of the position sensor demodulation; this is the selected configuration for the GRC flywheel modules. In the worst case for this test, the X1 PWM was set $50 \mathrm{~Hz}$ above the other four PWMs to induce beat frequency noise, and the remaining PWMS were set such that the $15^{\text {th }}$ harmonic was $90 \mathrm{~Hz}$ above the sensor carrier frequency. Note that this is by no means the worst-case configuration possible - if the other four PWMs were not synchronized, multiple sources of both types of noise could be generated; however, noise sources would be difficult to separate under these conditions. Thus, cell $\mathrm{H}$ represents the worst case for a controlled test.

Table 4. Best and Worst Configuration Test

\begin{tabular}{|c|l|l|l|c|}
\hline Cell & \multicolumn{1}{|c|}{ Test } & Config & \multicolumn{1}{|c|}{ Harmonic } & F $_{\text {PWM }}$ \\
\hline A & best case & synched & $15.41 n$ & $32,437.6$ \\
\hline $\mathbf{H}$ & beating \& & $X 1$ & $15 n+90+50$ & $33,389.3$ \\
& demod & Other 4 & $15 n+90$ & $33,339.3$ \\
\hline
\end{tabular}

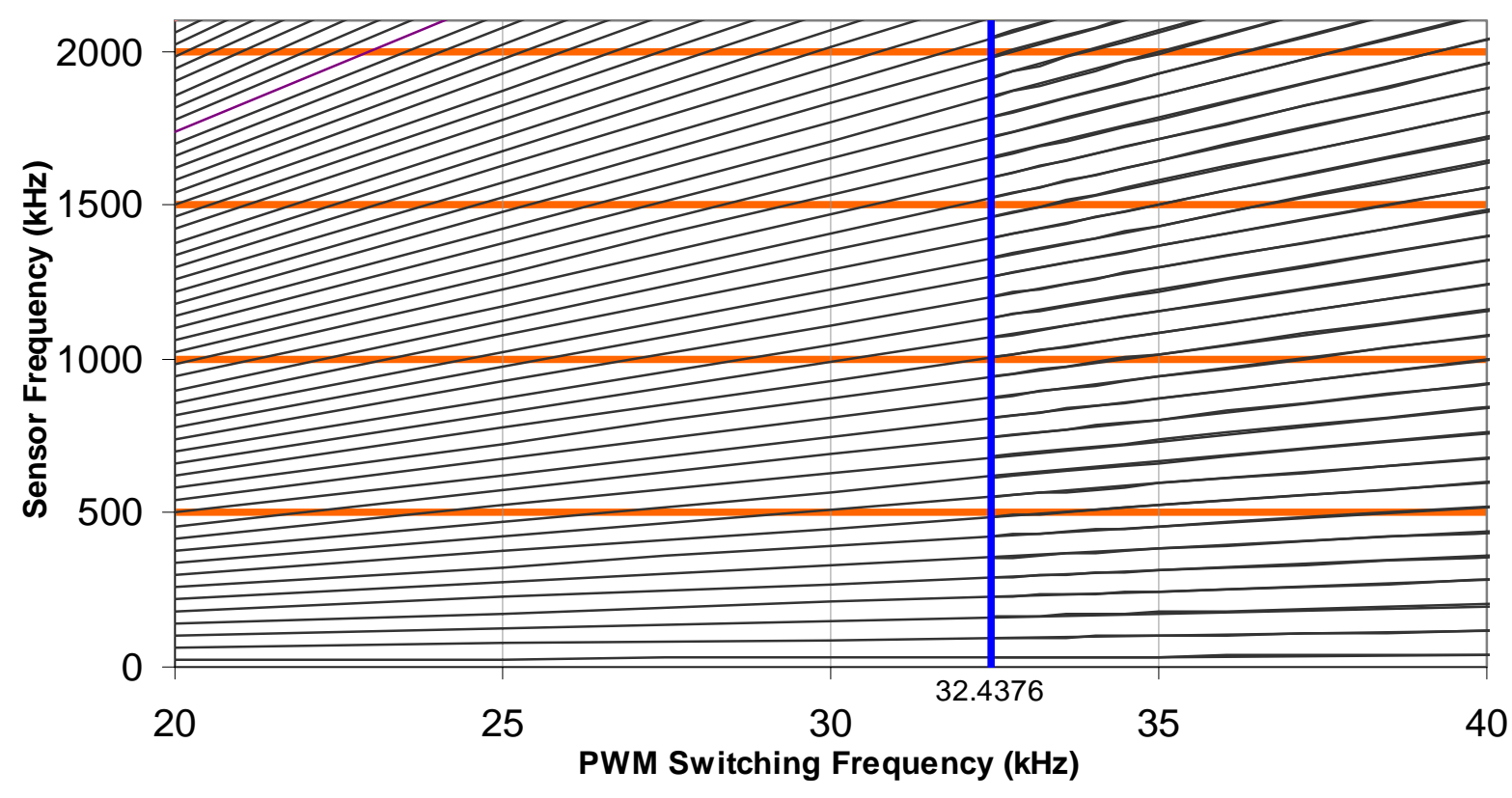

Figure 8. Synchronized PWM Switching Frequency Selection 
Figure 9 shows the best vs. worst case results. In the best case, the $60 \mathrm{~Hz}$ line noise and its harmonics is the most discernable noise source. The worst case configuration shows both the beat frequency and demodulation noise effects; note that many other noise frequencies also arise from interactions between these effects. In the inset graph the higher noise floor can be seen across the frequency range, particularly in the range between 300 and $1500 \mathrm{~Hz}$.

\section{Impact of Grounding and Shielding}

The data for this paper was collected two times, once when the initial observations were made and a second time for presentation quality data. During the interval between those tests the quality of the grounding and shielding setup for the flywheel module and its power electronics system was improved dramatically. A single point ground was employed, and a much larger fraction of the power and signal cables were converted to twisted shielded pairs. These changes reduced the magnitude of the effects observed in this paper significantly from the first work to the final data set, but allow for a lower noise environment overall.

\section{Conclusions}

Switching PWMs produce interference with eddy current position sensors. Two separate noise types were characterized - beat frequency noise and demodulation noise.
Beat frequency noise arises when multiple PWMs with different switching frequencies operate on a common $\mathrm{MB}$ actuator. This effect can be eliminated by synchronizing all of the PWMs in the system.

Demodulation noise is generated when odd harmonics of the PWM switching frequency fall near the carrier frequency of the position sensors. This problem can be avoided by selecting the PWM frequency such that no odd harmonics fall on the sensor demodulation frequency.

The selected configuration for the GRC flywheel modules, based on the study performed in this paper, has all five PWMs synchronized, and switching at a non-integer harmonic of the position sensor carrier frequency.

\section{$\underline{\text { References }}$}

[1] McLallin, K., Jansen, R., Fausz, J., Bauer, R., "Aerospace Flywheel Technology Development for IPACS Applications," NASA TM-2001-211093, October 2001.

[2] Dever, T. P., Palazzolo, A. B., Thomas, E. M., and Jansen, R. H., "Evaluation and Improvement of Eddy Current Position Sensors in Magnetically Suspended Flywheel Systems," July 2001 IECEC Conference Proceedings, Savannah, Georgia, 2001.

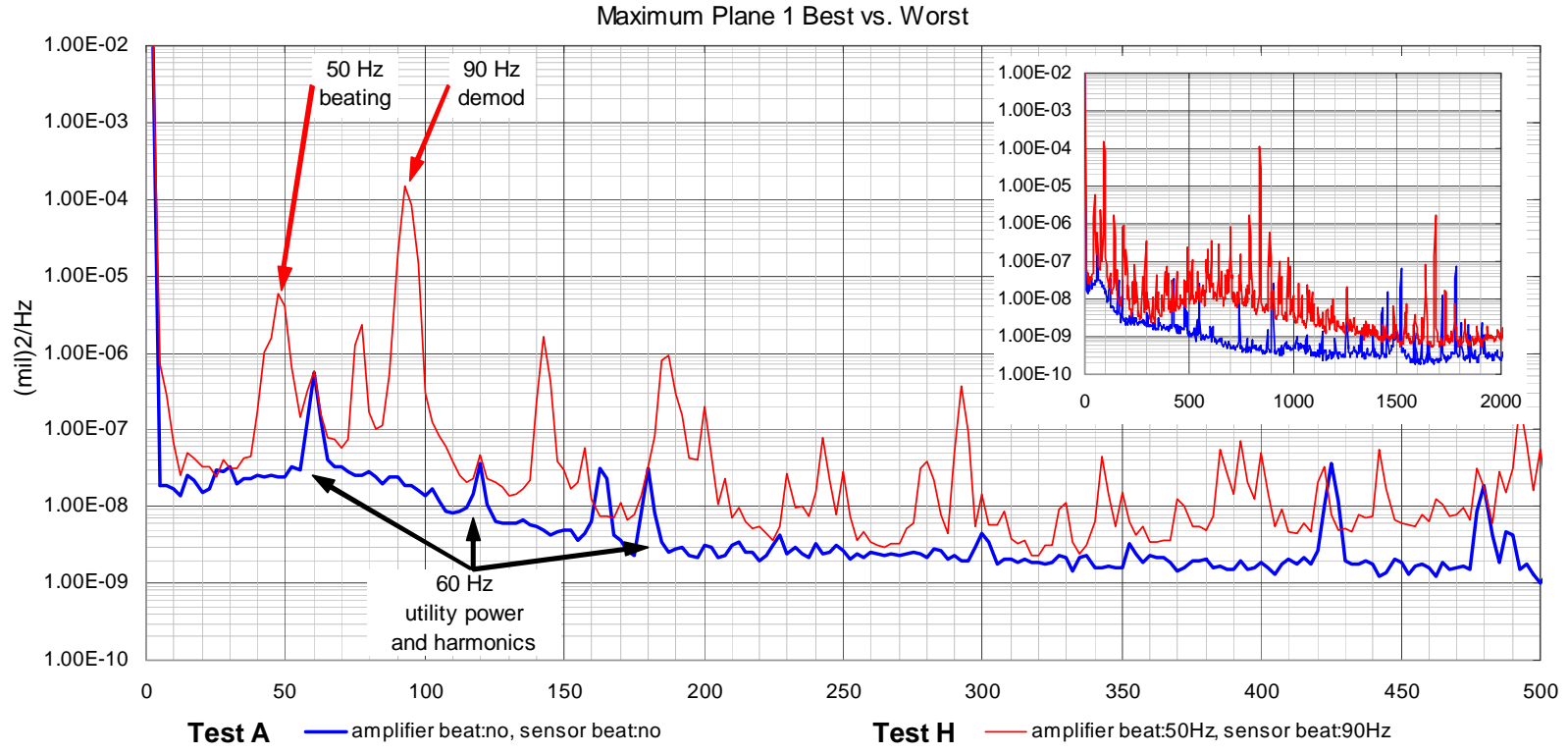

Figure 9. Demodulation and Beat Frequency Noise vs. Best Case 


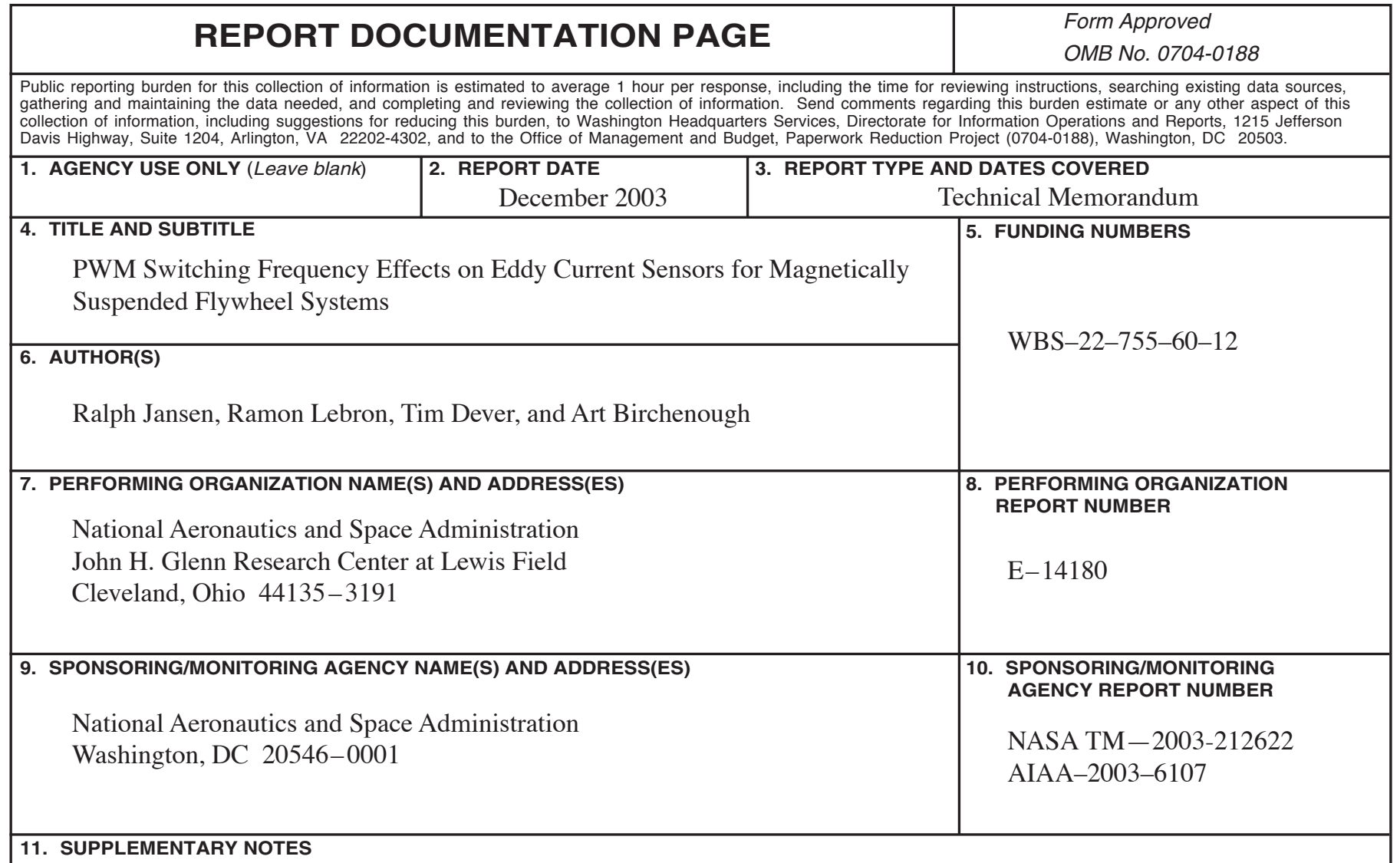

Prepared for the First International Energy Conversion Engineering Conference sponsored by the American Institute of Aeronautics and Astronautics, Portsmouth, Virginia, August 17-21, 2003. Ralph Jansen, University of Toledo, Toledo, Ohio 43606; Ramon Lebron and Art Birchenough, NASA Glenn Research Center; and Tim Dever, QSS Group, Inc., Cleveland, Ohio 44135. Responsible person, Ralph H. Jansen, organization code 5930, 216-433-6038.

\begin{tabular}{ll|l}
\hline 12a. DISTRIBUTION/AVAILABILITY STATEMENT & & 12b. DISTRIBUTION CODE \\
Unclassified - Unlimited & Distribution: Nonstandard & \\
Subject Categories: $20,33,37$, and 44 & \\
Available electronically at http://gltrs.grc.nasa.gov & \\
This publication is available from the NASA Center for AeroSpace Information, 301-621-0390. &
\end{tabular}

\section{ABSTRACT (Maximum 200 words)}

A flywheel magnetic bearing (MB) pulse width modulated power amplifier (PWM) configuration is selected to minimize noise generated by the PWMs in the flywheel position sensor system. Two types of noise are addressed: beat frequency noise caused by variations in PWM switching frequencies, and demodulation noise caused by demodulation of high order harmonics of the switching voltage into the MB control band. Beat frequency noise is eliminated by synchronizing the PWM switch frequencies, and demodulation noise is minimized by selection of a switching frequency which does not have harmonics at the carrier frequency of the sensor. The recommended MB PWM system has five synchronized PWMs switching at a non-integer harmonic of the sensor carrier.

\begin{tabular}{|c|c|c|c|}
\hline \multirow{3}{*}{\multicolumn{3}{|c|}{$\begin{array}{l}\text { 14. SUBJECT TERMS } \\
\text { Flywheels; Reaction wheels; Counter-rotating wheels; Electric motors; } \\
\text { Electromechanical devices }\end{array}$}} & \multirow{3}{*}{\begin{tabular}{|l|} 
15. NUMBER OF PAGES \\
13 \\
16. PRICE CODE
\end{tabular}} \\
\hline & & & \\
\hline & & & \\
\hline $\begin{array}{l}\text { 17. SECURITY CLASSIFICATION } \\
\text { OF REPORT }\end{array}$ & $\begin{array}{l}\text { 18. SECURITY CLASSIFICATION } \\
\text { OF THIS PAGE }\end{array}$ & $\begin{array}{l}\text { 19. SECURITY CLASSIFICATION } \\
\text { OF ABSTRACT }\end{array}$ & 20. LIMITATION OF ABSTRACT \\
\hline Unclassified & Unclassified & Unclassified & \\
\hline \multicolumn{3}{|l|}{ NSN 7540-01-280-5500 } & Standard Form 298 (Rev. 2-89) \\
\hline
\end{tabular}

